\title{
Activation of Dopamine D2 Receptor Alleviates Neuroinflammation and Neuronal Injury in Mice Model of Allergic Rhinitis With Olfactory Dysfunction
}

\section{Peiqiang Liu}

Renmin Hospital of Wuhan University: Wuhan University Renmin Hospital

\section{Danxue Qin}

Renmin Hospital of Wuhan University: Wuhan University Renmin Hospital Hao LV

Renmin Hospital of Wuhan University: Wuhan University Renmin Hospital

\section{Wenjun Fan}

Renmin Hospital of Wuhan University: Wuhan University Renmin Hospital

\section{Fangwei Zhou}

Renmin Hospital of Wuhan University: Wuhan University Renmin Hospital

\section{Ziang Gao}

Renmin Hospital of Wuhan University: Wuhan University Renmin Hospital

\section{Zezhang Tao}

Renmin Hospital of Wuhan University: Wuhan University Renmin Hospital

\section{YuXu( $\nabla$ xuy@whu.edu.cn )}

Department of Otolaryngology-Head and Neck Surgery, Renmin Hospital of Wuhan University, Wuhan, China;

\section{Research}

Keywords: Allergic rhinitis, Olfactory dysfunction, Dopamine D2 receptor, Neuroinflammation, AMPA receptor

Posted Date: October 1st, 2020

DOI: https://doi.org/10.21203/rs.3.rs-82487/v1

License: (a) (1) This work is licensed under a Creative Commons Attribution 4.0 International License. Read Full License 


\section{Abstract}

Background: Allergic rhinitis (AR) is a common chronic allergic disease of the upper airway that not only causes peripheral inflammation, but also induces neuroinflammation in the hippocampus, prefrontal cortex, olfactory bulb and other brain areas. Recent studies have suggested that the dopamine D2 receptor acts as a key target in regulating immune functions and neuroinflammatory reaction, which may be a promising target for AR-induced olfactory dysfunction (OD).

Methods: An AR mouse model with OD induced by ovalbumin (OVA) were constructed. A coculture system of olfactory bulb neurons (OBNs) and microglias was established. The buried food pellet test was to evaluate the olfactory function of the mice. Immunofluorescence staining, HE staining, ELISA, Western blotting, and TUNEL staining were also used to investigate the molecular mechanisms underlying the anti-inflammatory effects of the dopamine D2 receptor in AR-induced OD.

Results: We confirmed that AR mice with or without OD had the characteristics of $A R$, but the expression of the microglial marker CD11b and the related cytokines (TNF- $a, I L-1 \beta$ and IL-6) in the AR mice with OD were significantly increased in the olfactory bulb compared with those of mice without OD. Nasal administration of quinpirole, a dopamine $D 2$ receptor agonist, shortened the time to find the food pellets, inhibited the expression of TLR4/MyD88/NF-KB signalings and the levels of TNF-a, IL-1 $\beta$ and IL- 6 . In the coculture system of OBNs and microglias, quinpirole inhibited the release of TLR4/MyD88/NF-KB signalings-dependent inflammatory cytokines in the microglias, which was accompanied by decreased AMPA receptor GluR1, increased GluR2 and reduced TUNEL positive cells in the OBNs.

Conclusion: Activation of the dopamine D2 receptor inhibits the release of inflammatory cytokines through the microglia-dependent TLR4/MyD88/NF-KB signalings, alleviates AMPA receptor-mediated damage of the olfactory bulb, and protects olfactory function.

\section{Introduction}

Allergic rhinitis (AR) is a common clinical otorhinolaryngology disease that has a huge impact on public health. Olfactory dysfunction (OD) is a common concomitant symptom of $A R$, which impairs the ability to discriminate flavors, detect poisonous and pernicious gas from the environment [1]. Olfactory bulb, as a relay station for olfactory transmission, plays a crucial role in olfactory formation. Actually, microgliosis are representative pathological changes that develop during neuroinflammation of central nervous system (CNS) [2]. A close link between microglial hyperplasia of olfactory bulb and olfactory dysfunction has been reported in the patients and animal models of the neuroimmunological disorders, including experimental autoimmune encephalomyelitis (EAE), Alzheimer's disease (AD) and Parkinson's disease (PD) and so on [3-5]. Furthermore, recent studies have shown that airway allergen exposure directly induces neuroinflammation [6,7], such as increased Th2-type cytokines and nNOS in the olfactory bulb of airway inflammation animal models $[8,9]$. Therefore, alleviating neuroinflammation (like microglial hyperplasia) of the olfactory bulb may be expected to improve AR-induced OD. 
As an important catecholamine neurotransmitter, dopamine can be used as bridge molecule to connect the nervous and immune systems [10]. Recently, the anti-neuroinflammatory effects of the dopamine D2 receptor have been highlighted, and its agonists prevent the degeneration of dopaminergic neurons by inhibiting the TLR4/NF-KB pathway in PD mice [11]. Furthermore, the microglia-dependent TLR4/NF-KB pathway is a key link in inducing neuronal AMPA receptor (AMPAR) trafficking and subsequent excitotoxicity injury[11], which plays an important role in brain damage in many inflammatory diseases, such as peripheral inflammatory pain, autoimmune encephalopathy, brain injury, inflammatory bowel disease and others [12-15]. For example, the activation of glial purinergic signals by TLR4 can significantly increase the excitatory synaptic drive of CA1 neurons by modulating glutamate receptor trafficking [16]. Activation of TLR4 induces an increase in microglia-dependent TNF-a release, which can recruit calcium-permeable AMPAR into synapses [17]. In addition, excitability of the cerebral dentate gyrus after brain injury accompanied by increased TLR4 signaling is mediated by the synaptic AMPAR current, while the NMDAR, another glutamate receptor, does not change [18]. Consistent with this, blocking of TLR4 signaling after brain injury can reduce the calcium-permeable AMPAR current of granular cells in the dentate gyrus, reduce neural network excitability and epilepsy susceptibility $[19,20]$. Based on the above studies, we speculate that AR-induced OD may be accompanied with AMPAR-mediated neuronal damage induced by microglia activation, and dopamine $\mathrm{D} 2$ receptor agonists are expected to reverse this process.

In this study, we used an ovalbumin (OVA)-induced AR model with OD to detect microglial inflammation related indicators, and explored the effect of the dopamine D2 receptor agonist quinpirole on neuroinflammation in the olfactory bulb and olfactory function in vivo. Additionally, we established a coculture system of olfactory bulb neurons (OBNs) and microglias, and investigated the mechanism of quinpirole reversal of $O B N$ damage in vitro. Our results clearly demonstrated that activation of dopamine D2 receptor improves microglia-dependent neuroinflammation and restores olfactory damage.

\section{Materials And Methods}

\section{Establishment of the AR model with olfactory dysfunction}

The 6-8 week old mice were provided by the Animal Experiment Center of Renmin Hospital of Wuhan University. All experimental procedures were approved by the Animal Ethics Committee of Renmin Hospital of Wuhan University (License No. WDRM 20190419). The AR model with OD was established as described previously [21]. On days 0,7 , and $14,300 \mu \mathrm{L}$ PBS containing $50 \mu$ OVA (grade V; Sigma) and $1 \mathrm{mg}$ of aluminum hydroxide was administered by intraperitoneal injection for sensitization. On the $21 \mathrm{st}$ day, $20 \mu \mathrm{L}$ PBS containing $400 \mu \mathrm{g}$ OVA was administeredere intranasally once a day for 2 consecutive weeks for the challenge. The mice in the control (Ctr) group were given the same amount of PBS in the nasal cavity. Finally, the AR mice with OD were selected by the buried food pellet test (Fig. 1a).

\section{Buried food pellet test}


The buried food pellet test (BFPT) was used to evaluate the olfactory function of mice as previously described [22]. Briefly, the mice were fasted 18-24 hours before the test. In the test cage $(42 \mathrm{~cm}$ length $\times$ $28 \mathrm{~cm}$ width $\times 18.5 \mathrm{~cm}$ height), a food pellet of approximately $4 \mathrm{~g}$ was buried at a depth of $0.5 \mathrm{~cm}$ under the bedding. After 1 hour of habituation, the time it took the mice to grasp the food pellets with their front paws or teeth was recorded. If the food pellets were not found within 300 seconds (an average of three tests), it was identified as olfactory dysfunction: the AR mice with OD were selected based on this criterion. In addition, we measured the latency time of each mouse after the drug treatments.

\section{Drug treatment and experimental grouping}

The AR mice with OD were identified and randomly divided into the following groups: quinpirole (Quin, $3 \mathrm{mg} / \mathrm{kg}$, Sigma) was administered nasally every day for $3,6,9$, and 12 days, and the control group was given PBS in equal doses. The drug concentration and route of administration used was based on the previously published article [23], and the nasal-brain pathway allows the drugs to bypass the blood-brain barrier and enter the central nervous system. During this period, the mice was challenged with OVA every other day. The olfactory function was evaluated 24 hours after the administration, and the mice were used for the following experiments after being sacrificed (Fig. 3a).

\section{Coculture of olfactory bulb neurons and microglias}

The use of the Transwell co-cultivation system and magnetic bead sorting maintains the in vivo state of the microglias to a greater extent, and additionally recapitulates the relationship between microglias and neuroinflammation. As previously reported [24, 25], the microglias were isolated from the olfactory bulbs after successful modeling. The olfactory bulbs were enzymatically digested, and filtered through $70 \mu \mathrm{m}$ cell strainers to prepare the single cell suspension. The microglias were sorted with CD11b magnetic beads (Miltenyi Biotech). After 3 rounds of resuspending, loading, and washing, the positive cells on the sorting column were collected. Furthermore, the olfactory bulbs of mice were isolated within 3 days after birth, and digested with $0.25 \%$ pancreatin at $37^{\circ} \mathrm{C}$ for 15 minutes after removing the meninges and blood vessels. The cells were resuspended with DMEM/F12 medium containing 10\% FBS (Gibco), inoculated into a polylysine-coated culture plate, and cultured a humidified $\mathrm{CO}_{2}(5 \%)$ incubator at $37^{\circ} \mathrm{C}$. After 7 days, they were co-cultivated with purified microglias for 24 hours, and were simultaneously treated with quinpirole $(20 \mu \mathrm{mol} / \mathrm{L})$.

\section{HE staining}

After the mice were sacrificed, their noses were fixed in $4 \%$ paraformaldehyde for 48 hours, decalcified in $20 \%$ EDTA for 2 weeks, and then made into paraffin sections. After the paraffin sections were deparaffinized, hematoxylin was used to stain the nucleus and eosin was used to stain the cytoplasm. The morphology of the mouse nasal mucosa was then observed under a light microscope $(\times 400) ; 5$ fields on each slice were randomly selected, in which the number of eosinophils was counted under the microscope, and then averaged.

\section{Immunofluorescence staining}


The olfactory bulbs were fixed with $4 \%$ paraformaldehyde, embedded in slices, and baked. After the paraffin sections were completely dewaxed with xylene, $10 \%$ calf serum was added, and the section were placed at room temperature for 10 minutes. The sections were incubated with rabbit polyclonal antiCD11b antibody (1:500, Abcam) at $4{ }^{\circ} \mathrm{C}$ overnight, followed by a FITC-labeled goat anti-rabbit IgG (Abcam) at room temperature for 30 minutes. The sections were washed with water, blown dry, sealed with glycerin, and followed by observation under a fluorescence microscope (Olympus).

\section{TUNEL staining}

TUNEL staining was carried out according to the manufacturer's instructions (Servicebio). The cells were fixed with $4 \%$ paraformaldehyde for 30 minutes, ruptured by $0.2 \%$ Triton X-100 for 5 minutes, and incubated with $50 \mu \mathrm{l}$ TUNEL reaction solution at $37^{\circ} \mathrm{C}$ for 60 minutes in the dark. DAPI was used to stain the nucleus. The cells were observed and photographed under a fluorescence microscope (Olympus). In 6 non-repeating high-power $(\times 400)$ fields, the number of TUNEL-positive cells as a percentage of the number of DAPI-positive cells was used to calculate the positivity rate.

\section{ELISA}

The olfactory bulbs, culture supernatant and serum were collected after drug treatments, and the levels of inflammatory mediators were measured using ELISA kits of TNF-a, IL-6, IL-1 3 and OVA-specific IgE (BD Biosciences) according to the manufacturer's instructions, respectively. The experiments were repeated for three times.

\section{Western blot}

After the drug treatment, the total protein was extracted. RIPA lysis buffer containing a protease inhibitor and a phosphatase inhibitor was added to the tissues or cells, which were then placed on ice for 30 minutes. After centrifugation at $12000 \mathrm{~g}$ for 15 minutes at $4{ }^{\circ} \mathrm{C}$, the supernatant was extracted. The surface proteins were extracted according to the instructions of the Cell Fractionation Kit (Thermo Fisher). The protein concentration was measured by a BCA kit (Absin), and samples of $40 \mu \mathrm{g}$ were loaded onto the gel for SDS-PAGE electrophoresis. After SDS-PAGE electrophoresis, the proteins were transferred to a membrane, which was blocked in $5 \%$ skim milk for 1.5 hours. The following primary antibodies, which were incubated at $4{ }^{\circ} \mathrm{C}$ in a shaker overnight, were used: TLR4 (1:500, Santa Cruz), MyD88 (1:500, Santa Cruz), NF-kB P65 (1:1000, Santa Cruz), NF-kB p-P65 (1:1000, Santa Cruz), GluR1 (1:1000, Abcam), GluR2 (1:2000, Abcam), and $\beta 3$-tubulin (1:1000, Abcam). The secondary antibody was labeled with HRP (1:50000, Servicebio) and incubated with the membrane at room temperature for 1 hour. The blots were washed 3 times for 10 minutes. The bands were visualized with enhanced chemiluminescence (ECL, Millipore) using a gel imaging system (Bio-Rad). ImageJ was used to determine the gray value. Using $\beta 3-$ tubulin as the reference protein, the relative intensities of each target protein band were calculated.

\section{Statistical analysis}


All results were represented as mean \pm SEM. The data and graphs were analyzed by GraphPad Prism 8.0 (GraphPad Software, USA). The results were analyzed by one-way ANOVA followed by post hoc Tukey's tests for multiple comparisons. A p value $<0.05$ was considered significant.

\section{Results}

\section{Establishment of the mouse model of AR with olfactory dysfunction}

To verify this model, histopathology, OVA-specific IgE and allergic symptoms were evaluated, and the AR mice were divided into groups with or without OD by the buried food pellet test (BFPT). The incidence of OD observed was $68.46 \%$. HE staining showed that the infiltration of eosinophils was significantly increased in the submucosa of the AR mice with and without OD (Fig. 1b, c). The OVA-specific IgE levels of the AR mice with and without OD were significantly increased (Fig. 1d), and the frequency of sneezing and rubbing of these mice was also significantly increased (Fig. 1e). This finding suggests that the AR mice with or without OD exhibit the characteristics of $A R$, and the AR mice with OD selected met the needs of the subsequent experiments.

\section{Hyperactivity of the microglia from the olfactory bulb in AR mice with olfactory dysfunction}

To verify the relationship between AR-induced OD and neuroinflammation in the olfactory bulb, we detected the expression of microglial marker CD11b and the related cytokines TNF- $a$, IL-1 $\beta$ and IL- 6 in the olfactory bulb. Compared with the group without OD, the expression of CD11b, TNF-a, IL-1 $\beta$ and IL- 6 in the group with OD increased by $94.78 \%(P<0.01), 596.81 \%(P<0.01), 281.65 \%(P<0.01)$ and $247.78 \%(P<$ 0.01), respectively (Fig. 2a, b, c). Similarly, the expression of TLR4, MyD88, and NF-KB p-P65/P65 in the OD group increased by $86.10 \%(P<0.01), 45.67 \%(P<0.05)$ and $99.08 \%(P<0.01)$, compared with group without OD, respectively (Fig. 2d, e). However, the expression of the above proteins in the group without OD group was not significantly different from that of the control (Ctr) group. These results suggest that olfactory dysfunction is involved in microglia hyperactivity of the olfactory bulb and is related to the TLR4/NF-KB pathway.

\section{Quinpirole alleviates microglia-dependent neuroinflammation in vivo and in vitro}

To verify the effect of dopamine D2 receptor agonist quinpirole (Quin) on the neuroinflammation in the olfactory bulb, quinpirole was administered in vivo and in vitro to assess the olfactory function and the expression of TNF-a, IL-1 $\beta$ and IL-6. The buried food pellet test found that nasal administration of quinpirole can shorten the time to find the food pellets. Compared with OVA treatment only, on the 3rd, 6th, 9th and 12th days after treatment with quinpirole, the expression of TNF-a decreased by $10.31 \%$ ( $P>$ 0.05), 34.18\% ( $P<0.05), 51.65 \%(P<0.01)$ and $55.58(P<0.01)$, the expression of IL-1 $\beta$ decreased by 
2.09\% $(P>0.05), 6.23 \%(P>0.05), 20.94 \%(P<0.01)$ and 25.04\% $(P<0.01)$, and the expression of IL-6 also decreased by $9.64 \%(P>0.05), 16.28 \%(P<0.05), 27.25 \%(P<0.01)$ and $35.30 \%(P<0.01)$ (Fig. 3c-e), respectively. In the cultured microglia of AR mice with OD, TNF- $\alpha$, IL-1 $\beta$ and IL- 6 in the culture medium decreased by $54.45 \%(P<0.01), 40.73 \%(P<0.01)$ and $21.57 \%(P \otimes 0.05)$, respectively, after 24 hours of treatment with quinpirole (Fig. 3f). To further investigate the relationship among quinpirole, TLR4 and inflammation, we observed the effect of quinpirole on microglia treated with LPS, a TLR4 agonist. After 24 hours of treatment with quinpirole, TNF- $a$, IL-1 $\beta$ and IL- 6 decreased by $45.61 \%(P<0.01), 34.09 \%(P<$ $0.01)$ and $54.49 \%(P<0.01)$ compared with LPS treatment alone, respectively (Fig. $3 \mathrm{~g})$. The results suggest that quinpirole reverses microglia-dependent neuroinflammation induced by TLR4 and improve olfactory function.

\section{Quinpirole exerts anti-neuroinflammatory effects through the TLR4/NF-kB pathway}

Previous studies have shown that TLR4/NF-KB is a vital pathway by which microglia releases inflammatory factors [26-28]. Therefore, we explored quinpirole's effect on the expression of TLR4, MyD88, NF-KB P65 and NF-kB p-P65 in vivo and in vitro. Compared with OVA treatment alone, on the 3rd, 6th, 9th, and 12th day after nasal administration of quinpirole, TLR4 decreased by $45.52 \%(P<0.01)$, $55.59 \%(P<0.01), 70.85 \%(P<0.01)$ and 75.26\% $(P \llbracket 0.01)$, MyD88 decreased by $8.14 \%(P \otimes 0.05), 16.37 \%$ (Pख0.01), 51.62\% (P囚0.01) and 60.31\% (Pख0.01), and $p-P 65 / P 65$ also decreased by $4.26 \%(P>0.05)$, $19.50 \%(P<0.05), 61.55 \%(P<0.01)$ and 69.97\% $(P<0.01)$, respectively (Fig. 4a-d). In addition, after 24 hours of treatment with quinpirole in vitro, TLR4, MyD88, and p-P65/P65 in the microglia of AR mice with OD were reduced by $50.38 \%(P<0.01), 35.34 \%(P<0.01), 54.99 \%(P<0.01)$ and $54.99 \%(P \bowtie 0.05)$ (Fig. 5a, b). To further study the direct correlation between quinpirole and the TLR4/NF-KB pathway, we sorted the microglia of normal mice and observed the effect of quinpirole on microglia treated with LPS. After 24 hours of treatment with quinpirole, TLR4, MyD88 and p-P65/P65 decreased by 57.99\% $(P<0.01), 25.23 \%$ $(P<0.01)$ and $34.23 \%(P<0.05)$, respectively (Fig. $5 c, d)$. This suggests that quinpirole plays an antineuroinflammatory role directly through the TLR4/NF-KB pathway.

\section{Quinpirole alleviates AMPAR-mediated neuronal damage}

Numerous studies have reported that pro-inflammatory cytokines such as TNF- $\alpha$ and IL-1 $\beta$ participate in the regulation of AMPAR trafficking, and result in increased GluR1 and decreased GluR2, which are the key links in inducing neuronal damage [29-31]. However, whether quinpirole can relieve AMPAR-mediated damage induced by microglia hyperactivity remains to be studied. On the 3rd, 6th, 9th and 12th day after treatment with quinpirole, the surface/total expression of GluR1 was reduced by $6.74 \%(P>0.05), 21.30 \%$ $(P<0.05), 26.42 \%(P<0.05)$ and $47.86 \%(P \otimes 0.01)$ (Fig. 6a, b), and that of GluR2 increased by $4.51 \%(P>$ $0.05), 18.68 \%(P<0.05), 50.67 \%(P<0.01)$ and $60.06 \%(P \otimes 0.01)$, respectively, compared with OVA treatment alone (Fig. 6c, d). In the coculture system of OBNs and microglia extracted from AR mice with OD after 24 hours of quinpirole treatment, the surface/total expression of GluR1 of OBNs reduced by 86.34\% (Pख0.01) (Fig. 7a, b), that of GluR2 increased by 69.93\% (Pख0.01) (Fig. 7c, d), and TUNEL-positive 
cells reduced by $81.28 \%(\mathrm{P} \otimes 0.01)$ (Fig. 7e, f). The above results suggest that AR with OD is related to microglia hyperactivity in the olfactory bulb and that quinpirole can improve AMPAR-mediated neuronal damage induced by the microglia.

\section{Disccussion}

Several studies on humans and rodents have shown that the intranasal or nebulized inhalation in allergen-sensitized animals induced avoidance behavior and activated limbic brain areas [8, 9, 32, 33]. OVA or pollen-induced AR rats produced TH2 cytokines in the olfactory bulb and prefrontal cortex but not in the temporal cortex and hypothalamus, and increased brain activity was observed by functional MRI [8]. Asthma induces activation of the microglias in the hippocampus and prefrontal cortex, elevated levels of TNF- $\alpha$ and IL-1 $\beta$, and a significant loss of neurons in the brain [33]. In the brain responses observed in allergic asthma, atopic dermatitis and multiple sclerosis, the levels of CCL11 increase, which promote eosinophil infiltration and subsequent neuronal damage in the affected area, followed by facilitation of the migration of microglias and ROS production, which ultimately enhance neurotoxicity induced by glutamate [34-36]. Additionally, the choroid plexus is an important structure of the ventricle with bloodbrain barrier (BBB) permeability, which has a high level of expression of IL-4Ra. Macrophages of the choroid plexus that respond to IL-4 can release pro-inflammatory cytokines, which then leak into the brain to promote the microglia to produce a second wave of cytokines [37]. Endothelin-1 produced by inflammatory tissue may increase BBB permeability and activate microglia expressing endothelin receptor $B$ through the damaged BBB [38]. Other hypotheses cite the role of IL-1 $\beta$ in allergic reactions, which activates the hypothalamic-pituitary-adrenal (HPA) axis, stimulates the release of cortisol and serotonin, and leads to mood disorders [39]. This study also showed that AR-induced OD was closely related to neuroinflammation of the olfactory bulb. The expression of microglia marker protein CD11b, TNF- $a$, IL-1 $\beta$ and IL- 6 in the olfactory bulbs were significantly increased in the AR mice with OD, which is similar to the findings in the hippocampus [32]. However, the mechanism of allergen-induced damage to the olfactory bulb is not clear.

Numerous studies have shown that TLR4 is a key molecule that regulates the immune response during CNS infection and injury [26]. After activation in the brain, TLR4 binds to MyD88 to relieve the inhibitory effect of ІкB on NF-kB, promote NF-kB nuclear translocation, stimulate inflammation-related gene expression, and promote the synthesis and release of TNF-a, IL-1 $\beta$ and IL-6 [26-28]. Our research found that the dopamine D2 receptor agonist quinpirole inhibited the expression of TLR4 and downstream signal molecules in the olfactory bulb, and the release of inflammatory cytokines. Similar to these results, quinpirole suppressed the expression of TLR4/NF-KB pathway in PD mice by increasing the expression of $\beta A r r 2$, thereby preventing dopaminergic neuron degeneration [11]. In addition, the regulatory effect of dopamine D2 receptor on neuroinflammation is also related to the mechanisms, such as NLRP3 inflammasome, renin-angiotensin system (RAS) and aB-crystallin. For example, the selective dopamine D2 receptor agonist LY171555 inhibited the activation of NLRP3 inflammasomes in the substantia nigra pars compacta of PD mice, thereby further controling the assembly process of the inflammasomes [40]. L-DOPA suppressed the production of angiotensinogen in astrocytes through the dopamine D2 receptor, 
thereby inhibiting microglia-mediated inflammation and neuronal oxidative stress caused by excessive activation of RAS [41]. Furthermore, quinpirole reduceed the level of pro-inflammatory mediators in the substantia nigra of PD mice by increasing the expression of aB-crystallin [42]. This study also suggests that dopamine D2 receptor activation can reduce the TLR4/NF-KB-dependent release of TNF- $\mathrm{a}$, IL-1 $\beta$ and IL-6 in the microglia and alleviate the inflammatory response of the olfactory bulb.

Recent studies have shown that the microglia releases the pro-inflammatory cytokines TNF- $\alpha$ and IL-1 $\beta$ to participate in the regulation of AMPAR trafficking, which is a key link in inducing neuroinflammatory damage [29-31]. The AMPAR trafficking results in intracellular $\mathrm{Ca}^{2+}$ overload, triggering a series of neurotoxic cascades such as mitochondrial damage, oxidative stress, and cell death $[43,44]$. In a cervical spinal cord contusion model, the number of GluR1-containing AMPARs at the ipsilateral synapse increased after injury. In vivo nanoinjection of TNF-a into the ventral horn of the spinal cord resulted in increased GluR1 and decreased GluR2 at extrasynaptic and synaptic plasma membrane sites [45]. In subsequent studies, the expression of the GluR1 subunit was increased in human NT2-N neurons exposed to TNF-a, leading to an increased susceptibility to kainate-induced necrosis, which was related to the A-Smase/NF- $K$ B pathway [46]. Similar findings were observed in hippocampal neurons and lumbar motor neurons, in which TNF-a or IL-1 $\beta$ increased the surface expression of GluR1-containing AMPAR, accompanied by a significant increase in AMPAR-mediated excitatory postsynaptic currents [16, 47]. IL-1 $\beta$ promote the release of NOS and presynaptic glutamate, and ultimately lead to enhanced AMPAR activity [48]. In addition, IL-1 $\beta$ in the brain is involved in microglia-related inflammatory pain and leads to the depolarization of paraventricular nucleus neurons or the membrane hyperpolarization of hypothalamic neurons, which is associated with abnormal AMPAR activation [49]. Our results found that the activation of the dopamine D2 receptor inhibited the release of TNF- $a, \mathrm{IL}-1 \beta$ and IL-6, accompanied with increased GluR1 and decreased GluR2, thereby alleviating the excitotoxicity mediated by AMPARs in the olfactory bulb.

In summary, inhibiting neuroinflammation is a promising strategy in the treatment of neurological diseases. For example, quinpirole prevents neuroinflammation-mediated dopaminergic neuron degeneration in PD [11] and reduces microglia-mediated inflammation [41]. After the occurrence of intracerebral hemorrhage $(\mathrm{ICH})$ or $\mathrm{PD}$, exogenous quinpirole inhibit neuroinflammation and improve the outcome of the nervous system $[23,42]$. The dopamine D2 receptor agonist bromocriptine significantly inhibited the hyperactivity of glial cells and reduced the production of TNF-a in the spinal cord of amyotrophic laternal sclerosis (ALS), thereby preventing the loss of motor neurons [50,51]. Therefore, the dopamine D2 receptor may be an effective target to improve the neuroinflammation in the olfactory bulb, and ultimately help to develop drugs for the treatment of AR with olfactory dysfunction.

\section{Conclusion}

In conclusion, the microglias of olfactory bulb were abnormally activated in AR with olfactory dysfunction, followed by the upregulation of TLR4/MyD88/NF-KB signals, TNF-a, IL-1 $\beta$ and IL-6. Quinpirole, a dopamine D2 receptor agonist, can improve TLR4/MyD88/NF-kB signalings-dependent 
neuroinflammation and AMPAR-mediated exitotoxicity, thereby helps to restore olfactory function. Our findings suggest an association among dopamine D2 receptor, neuroinflammation and AMPAR-mediated neuronal damage in olfactory bulb, providing a novel target for the treatment of olfactory dysfunction induced by AR.

\section{Abbreviations}

AMPAR

alpha-amino-3-hydroxy-5-methyl-4-isoxazole propionic acid receptor; AR:Allergic rhinitis; BBB:blood-brain barrier; BFPT:Buried food pellet test; CCL11:C-C motif chemokine 11; CNS:Central nervous system; IL13:Interleukin 1 beta; IL-6:Interleukin 6; MyD88:Myeloid differentiation factor 88; NF-kB:Nuclear factor-kB; OBN:Olfactory bulb neuron; OD:Olfactory dysfunction; OVA:Ovalbumin; TLR4:Toll-like receptor 4; TNFa:Tumor necrosis factor alpha; TUNEL:Terminal deoxynUcleotidyl transferase Nick-End Labeling.

\section{Declarations}

\section{Acknowledgements}

Not applicable.

\section{Authors' contributions}

PQ Liu and Y Xu conceptualised and designed the research; PQ Liu, DX Qin, H Lv and WJ Fan performed the research; FW Zhou and ZA Gao analyzed the data; PQ Liu, DX Qin and Y Xu wrote the manuscript. The authors read and approved the final manuscript.

\section{Funding}

This work was supported by grants from The National Natural Science Foundation of China (NSFC): No. 81770986 (Yu Xu); No. 81371070 (Yu Xu).

\section{Availability of data and materials}

The datasets supporting the conclusions of this article are included within the article.

\section{Ethics approval and consent to participate}

The study was approved by the Animal Ethics Committee of Renmin Hospital of Wuhan University.

\section{Consent for publication}

Not applicable.

\section{Competing interests}


The authors declare no conflict of interest.

\section{Author details}

1 Department of Otolaryngology-Head and Neck Surgery, Renmin Hospital of Wuhan University, Wuhan, China; 2 Research Institute of Otolaryngology-Head and Neck Surgery, Renmin Hospital of Wuhan University, Wuhan, China

\section{References}

1. Guss J, Doghramji L, Reger C, Chiu AG. Olfactory dysfunction in allergic rhinitis. ORL J Otorhinolaryngol Relat Spec. 2009;71:268-72.

2. Ohja K, Gozal E, Fahnestock M, Cai L, Cai J, Freedman JH, Switala A, El-Baz A, Barnes GN. Neuroimmunologic and Neurotrophic Interactions in Autism Spectrum Disorders: Relationship to Neuroinflammation. Neuromolecular Med. 2018;20:161-73.

3. Kim J, Choi Y, Ahn M, Jung K, Shin T. Olfactory Dysfunction in Autoimmune Central Nervous System Neuroinflammation. Mol Neurobiol. 2018;55:8499-508.

4. Kohl Z, Schlachetzki JC, Feldewerth J, Hornauer P, Munch M, Adame A, Riemenschneider MJ, Winkler $\mathrm{J}$, Masliah E. Distinct Pattern of Microgliosis in the Olfactory Bulb of Neurodegenerative Proteinopathies. Neural Plast. 2017;2017:3851262.

5. Doorn KJ, Goudriaan A, Blits-Huizinga C, Bol JG, Rozemuller AJ, Hoogland PV, Lucassen PJ, Drukarch $B$, van de Berg WD, van Dam AM. Increased amoeboid microglial density in the olfactory bulb of Parkinson's and Alzheimer's patients. Brain Pathol. 2014;24:152-65.

6. Rosenkranz MA, Busse WW, Johnstone T, Swenson CA, Crisafi GM, Jackson MM, Bosch JA, Sheridan JF, Davidson RJ. Neural circuitry underlying the interaction between emotion and asthma symptom exacerbation. Proc Natl Acad Sci U S A. 2005;102:13319-24.

7. Costa-Pinto FA, Basso AS, Britto LR, Malucelli BE, Russo M. Avoidance behavior and neural correlates of allergen exposure in a murine model of asthma. Brain Behav Immun. 2005;19:52-60.

8. Tonelli LH, Katz M, Kovacsics CE, Gould TD, Joppy B, Hoshino A, Hoffman G, Komarow H, Postolache TT. Allergic rhinitis induces anxiety-like behavior and altered social interaction in rodents. Brain Behav Immun. 2009;23:784-93.

9. Chen SD, Wen ZH, Chang WK, Chan KH, Tsou MT, Sung CS, Tang GJ. Acute effect of methylprednisolone on the brain in a rat model of allergic asthma. Neurosci Lett. 2008;440:87-91.

10. Sarkar C, Basu B, Chakroborty D, Dasgupta PS, Basu S. The immunoregulatory role of dopamine: an update. Brain Behav Immun. 2010;24:525-8.

11. Du RH, Zhou Y, Xia ML, Lu M, Ding JH, Hu G. alpha-Synuclein disrupts the anti-inflammatory role of Drd2 via interfering beta-arrestin2-TAB1 interaction in astrocytes. J Neuroinflammation. 2018;15:258.

12. Choi JI, Svensson $\mathrm{Cl}$, Koehrn FJ, Bhuskute A, Sorkin LS. Peripheral inflammation induces tumor necrosis factor dependent AMPA receptor trafficking and Akt phosphorylation in spinal cord in 
addition to pain behavior. Pain. 2010;149:243-53.

13. Levite M, Glutamate. T cells and multiple sclerosis. J Neural Transm (Vienna). 2017;124:775-98.

14. Perez-Polo JR, Rea HC, Johnson KM, Parsley MA, Unabia GC, Xu GY, Prough D, DeWitt DS, PaulucciHolthauzen AA, Werrbach-Perez K, Hulsebosch CE. Inflammatory cytokine receptor blockade in a rodent model of mild traumatic brain injury. J Neurosci Res. 2016;94:27-38.

15. Nyuyki KD, Pittman QJ. Toward a better understanding of the central consequences of intestinal inflammation. Ann N Y Acad Sci. 2015;1351:149-54.

16. Beattie EC, Stellwagen D, Morishita W, Bresnahan JC, Ha BK, Von Zastrow M, Beattie MS, Malenka RC. Control of synaptic strength by glial TNFalpha. Science. 2002;295:2282-5.

17. Pribiag H, Stellwagen D. Neuroimmune regulation of homeostatic synaptic plasticity. Neuropharmacology. 2014;78:13-22.

18. Li Y, Korgaonkar AA, Swietek B, Wang J, Elgammal FS, Elkabes S, Santhakumar V. Toll-like receptor 4 enhancement of non-NMDA synaptic currents increases dentate excitability after brain injury. Neurobiol Dis. 2015;74:240-53.

19. Korgaonkar AA, Li Y, Sekhar D, Subramanian D, Guevarra J, Swietek B, Pallottie A, Singh S, Kella K, Elkabes S, Santhakumar V. Toll-like Receptor 4 Signaling in Neurons Enhances Calcium-Permeable alpha-Amino-3-Hydroxy-5-Methyl-4-Isoxazolepropionic Acid Receptor Currents and Drives PostTraumatic Epileptogenesis. Ann Neurol. 2020;87:497-515.

20. Korgaonkar AA, Nguyen S, Li Y, Sekhar D, Subramanian D, Guevarra J, Pang KCH, Santhakumar V. Distinct cellular mediators drive the Janus faces of toll-like receptor 4 regulation of network excitability which impacts working memory performance after brain injury. Brain Behav Immun. 2020.

21. Wang X, Zhu Y, Ni D, Lv W, Gao Z, Qi F. Intranasal application of glucocorticoid alleviates olfactory dysfunction in mice with allergic rhinitis. Exp Ther Med. 2017;14:3971-8.

22. Talaga AK, Dong FN, Reisert J, Zhao H. Cilia- and Flagella-Associated Protein 69 Regulates Olfactory Transduction Kinetics in Mice. J Neurosci. 2017;37:5699-710.

23. Zhang Y, Chen Y, Wu J, Manaenko A, Yang P, Tang J, Fu W, Zhang JH. Activation of Dopamine D2 Receptor Suppresses Neuroinflammation Through alphaB-Crystalline by Inhibition of NF-kappaB Nuclear Translocation in Experimental ICH Mice Model. Stroke. 2015;46:2637-46.

24. Holt LM, Stoyanof ST, Olsen ML. Magnetic Cell Sorting for In Vivo and In Vitro Astrocyte, Neuron, and Microglia Analysis. Curr Protoc Neurosci. 2019;88:e71.

25. Nikodemova M, Watters JJ. Efficient isolation of live microglia with preserved phenotypes from adult mouse brain. J Neuroinflammation. 2012;9:147.

26. Lin ST, Wang Y, Xue Y, Feng DC, Xu Y, Xu LY. Tetrandrine suppresses LPS-induced astrocyte activation via modulating IKKs-lkappaBalpha-NF-kappaB signaling pathway. Mol Cell Biochem. 2008;315:41-9.

27. Zhang Z, Qin P, Deng Y, Ma Z, Guo H, Guo H, Hou Y, Wang S, Zou W, Sun Y, Ma Y, Hou W. The novel estrogenic receptor GPR30 alleviates ischemic injury by inhibiting TLR4-mediated microglial 
inflammation. J Neuroinflammation. 2018;15:206.

28. Guo LT, Wang SQ, Su J, Xu LX, Ji ZY, Zhang RY, Zhao QW, Ma ZQ, Deng XY, Ma SP. Baicalin ameliorates neuroinflammation-induced depressive-like behavior through inhibition of toll-like receptor 4 expression via the PI3K/AKT/Fox01 pathway. J Neuroinflammation. 2019;16:95.

29. Cabrera-Pastor A, Hernandez-Rabaza V, Taoro-Gonzalez L, Balzano T, Llansola M, Felipo V. In vivo administration of extracellular cGMP normalizes TNF-alpha and membrane expression of AMPA receptors in hippocampus and spatial reference memory but not IL-1beta, NMDA receptors in membrane and working memory in hyperammonemic rats. Brain Behav Immun. 2016;57:360-70.

30. Yan X, Li F, Maixner DW, Yadav R, Gao M, Ali MW, Hooks SB, Weng HR. Interleukin-1 beta released by microglia initiates the enhanced glutamatergic activity in the spinal dorsal horn during paclitaxelassociated acute pain syndrome. Glia. 2019;67:482-97.

31. Lai AY, Swayze RD, El-Husseini A, Song C. Interleukin-1 beta modulates AMPA receptor expression and phosphorylation in hippocampal neurons. J Neuroimmunol. 2006;175:97-106.

32. Yang S, Wu J, Zhang Q, Li X, Liu D, Zeng B, Liu Z, Kang H, Zhong Z. Allergic Rhinitis in Rats Is Associated with an Inflammatory Response of the Hippocampus. Behav Neurol. 2018;2018:8750464.

33. Xia MX, Ding X, Qi J, Gu J, Hu G, Sun XL. Inhaled budesonide protects against chronic asthmainduced neuroinflammation in mouse brain. J Neuroimmunol. 2014;273:53-7.

34. Teixeira MM, Wells TN, Lukacs NW, Proudfoot AE, Kunkel SL, Williams TJ, Hellewell PG. Chemokineinduced eosinophil recruitment. Evidence of a role for endogenous eotaxin in an in vivo allergy model in mouse skin. J Clin Invest. 1997;100:1657-66.

35. Parajuli B, Horiuchi H, Mizuno T, Takeuchi H, Suzumura A. CCL11 enhances excitotoxic neuronal death by producing reactive oxygen species in microglia. Glia. 2015;63:2274-84.

36. Isobe N, Kanamori Y, Yonekawa T, Matsushita T, Shigeto H, Kawamura N, Kira J. First diagnostic criteria for atopic myelitis with special reference to discrimination from myelitis-onset multiple sclerosis. J Neurol Sci. 2012;316:30-5.

37. Han L, Wang L, Tang S, Yuan L, Wu S, Du X, Xiang Y, Qu X, Liu H, Luo H, Qin X, Liu C. ITGB4 deficiency in bronchial epithelial cells directs airway inflammation and bipolar disorder-related behavior. $\mathrm{J}$ Neuroinflammation. 2018;15:246.

38. Yamasaki R, Fujii T, Wang B, Masaki K, Kido MA, Yoshida M, Matsushita T, Kira JI. Allergic Inflammation Leads to Neuropathic Pain via Glial Cell Activation. J Neurosci. 2016;36:11929-45.

39. Nanda MK, LeMasters GK, Levin L, Rothenberg ME, Assa'ad AH, Newman N, Bernstein D, KhuranaHershey G, Lockey JE, Ryan PH. Allergic Diseases and Internalizing Behaviors in Early Childhood. Pediatrics. 2016;137.

40. Zhu J, Hu Z, Han X, Wang D, Jiang Q, Ding J, Xiao M, Wang C, Lu M, Hu G. Dopamine D2 receptor restricts astrocytic NLRP3 inflammasome activation via enhancing the interaction of beta-arrestin2 and NLRP3. Cell Death Differ. 2018;25:2037-49.

41. Dominguez-Meijide A, Rodriguez-Perez Al, Diaz-Ruiz C, Guerra MJ, Labandeira-Garcia JL. Dopamine modulates astroglial and microglial activity via glial renin-angiotensin system in cultures. Brain 
Behav Immun. 2017;62:277-90.

42. Shao W, Zhang SZ, Tang M, Zhang XH, Zhou Z, Yin YQ, Zhou QB, Huang YY, Liu YJ, Wawrousek E, Chen T, Li SB, Xu M, Zhou JN, Hu G, Zhou JW. Suppression of neuroinflammation by astrocytic dopamine D2 receptors via alphaB-crystallin. Nature. 2013;494:90-4.

43. Lin DT, Huganir RL. PICK1 and phosphorylation of the glutamate receptor 2 (GluR2) AMPA receptor subunit regulates GluR2 recycling after NMDA receptor-induced internalization. J Neurosci. 2007;27:13903-8.

44. Isaac JT, Ashby MC, McBain CJ. The role of the GluR2 subunit in AMPA receptor function and synaptic plasticity. Neuron. 2007;54:859-71.

45. Ferguson AR, Christensen RN, Gensel JC, Miller BA, Sun F, Beattie EC, Bresnahan JC, Beattie MS. Cell death after spinal cord injury is exacerbated by rapid TNF alpha-induced trafficking of GluR2-lacking AMPARs to the plasma membrane. J Neurosci. 2008;28:11391-400.

46. Yu Z, Cheng G, Wen X, Wu GD, Lee WT, Pleasure D. Tumor necrosis factor alpha increases neuronal vulnerability to excitotoxic necrosis by inducing expression of the AMPA-glutamate receptor subunit GluR1 via an acid sphingomyelinase- and NF-kappaB-dependent mechanism. Neurobiol Dis. 2002;11:199-213.

47. Han P, Whelan PJ. Tumor necrosis factor alpha enhances glutamatergic transmission onto spinal motoneurons. J Neurotrauma. 2010;27:287-92.

48. Brough D, Le Feuvre RA, Wheeler RD, Solovyova N, Hilfiker S, Rothwell NJ, Verkhratsky A. Ca2 + stores and $\mathrm{Ca} 2+$ entry differentially contribute to the release of IL-1 beta and IL-1 alpha from murine macrophages. J Immunol. 2003;170:3029-36.

49. Liu T, Jiang CY, Fujita T, Luo SW, Kumamoto E. Enhancement by interleukin-1beta of AMPA and NMDA receptor-mediated currents in adult rat spinal superficial dorsal horn neurons. Mol Pain. 2013;9:16.

50. Tanaka K, Kanno T, Yanagisawa Y, Yasutake K, Hadano S, Yoshii F, Ikeda JE. Bromocriptine methylate suppresses glial inflammation and moderates disease progression in a mouse model of amyotrophic lateral sclerosis. Exp Neurol. 2011;232:41-52.

51. Iwasaki Y, Ikeda K, Shiojima T, Tagaya N, Kobayashi T, Kinoshita M. Bromocriptine prevents neuron damage following inhibition of superoxide dismutase in cultured ventral spinal cord neurons. Neurol Res. 1997;19:389-92.

\section{Figures}


A BFPT

D0

D7

D14

D21

BFPT

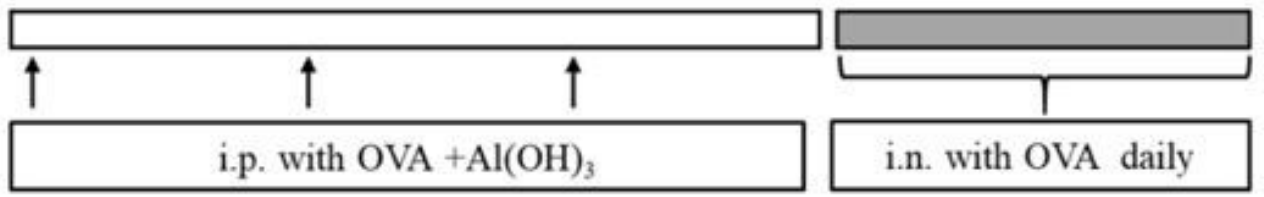

B

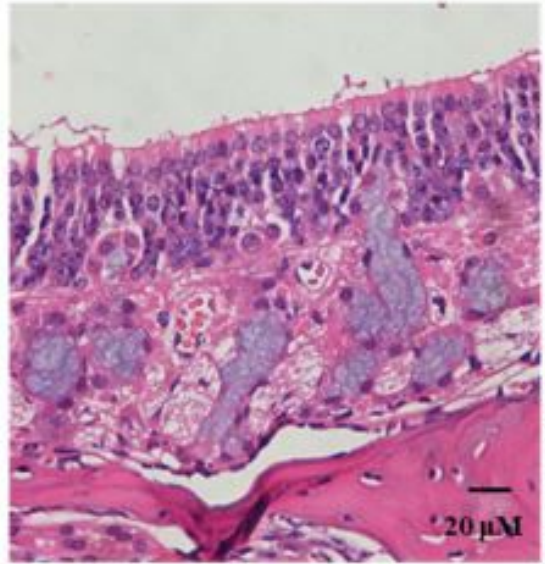

$\mathrm{Ctr}$

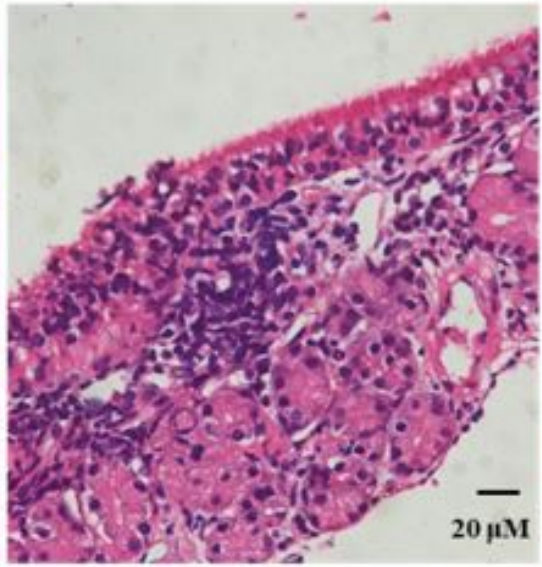

$\mathrm{AR}$ without $\mathrm{OD}$

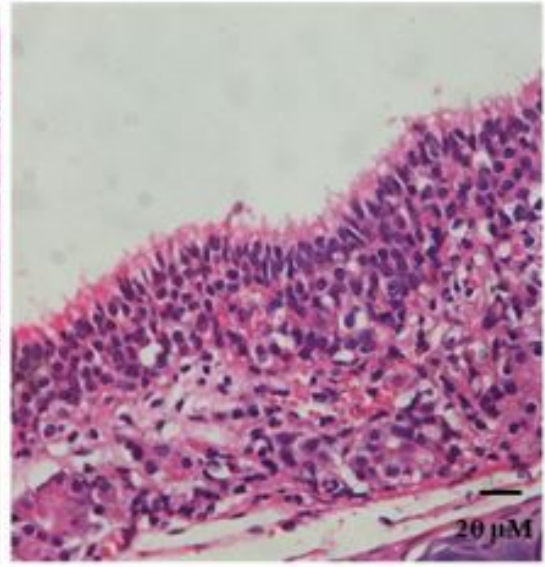

$A R$ with $O D$
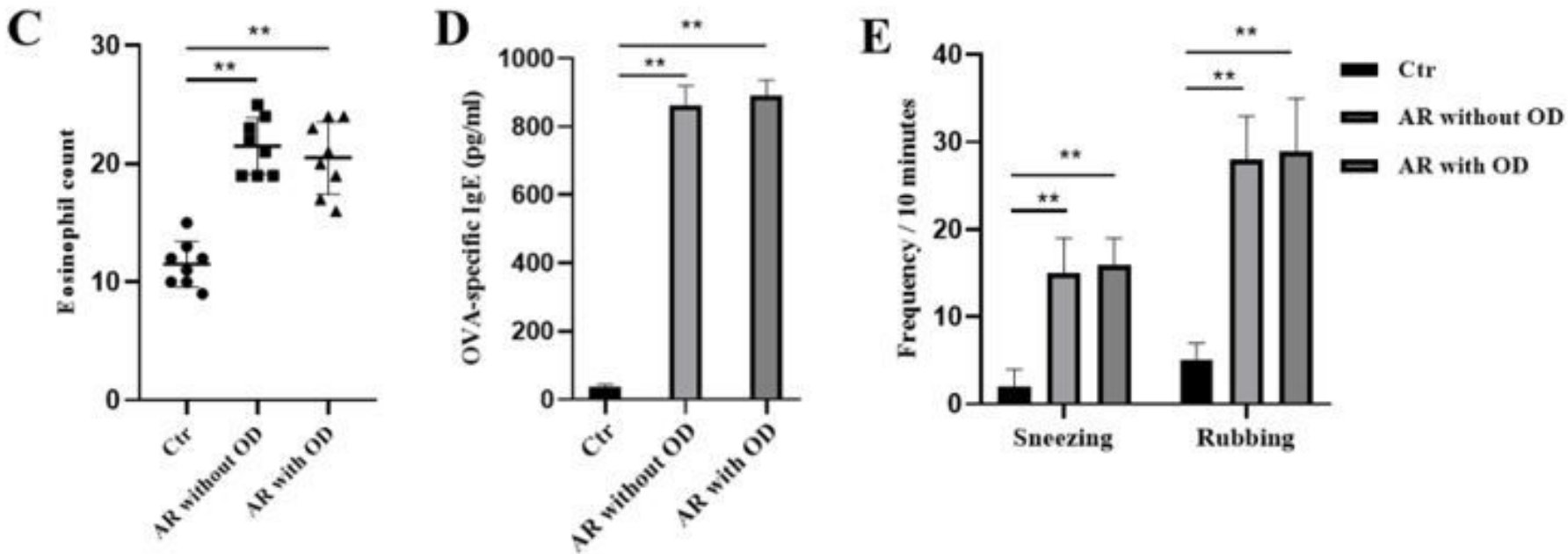

\section{Figure 1}

Establishment of the AR mice model with olfactory dysfunction (OD). a Protocol for the mice model of AR with OD. i.p., Intraperitoneal; i.n., intranasal. b, c Eosinophils were counted in six random high-power fields $(\times 400)$ by HE staining. $\mathrm{d}$ OVA-specific IgE in serum was measured by ELISA. e Symptoms of sneezing and rubbing were counted in 10 minutes after final challenge. * $P \bowtie 0.05$, ** $P \bowtie 0.01, n=8$ 


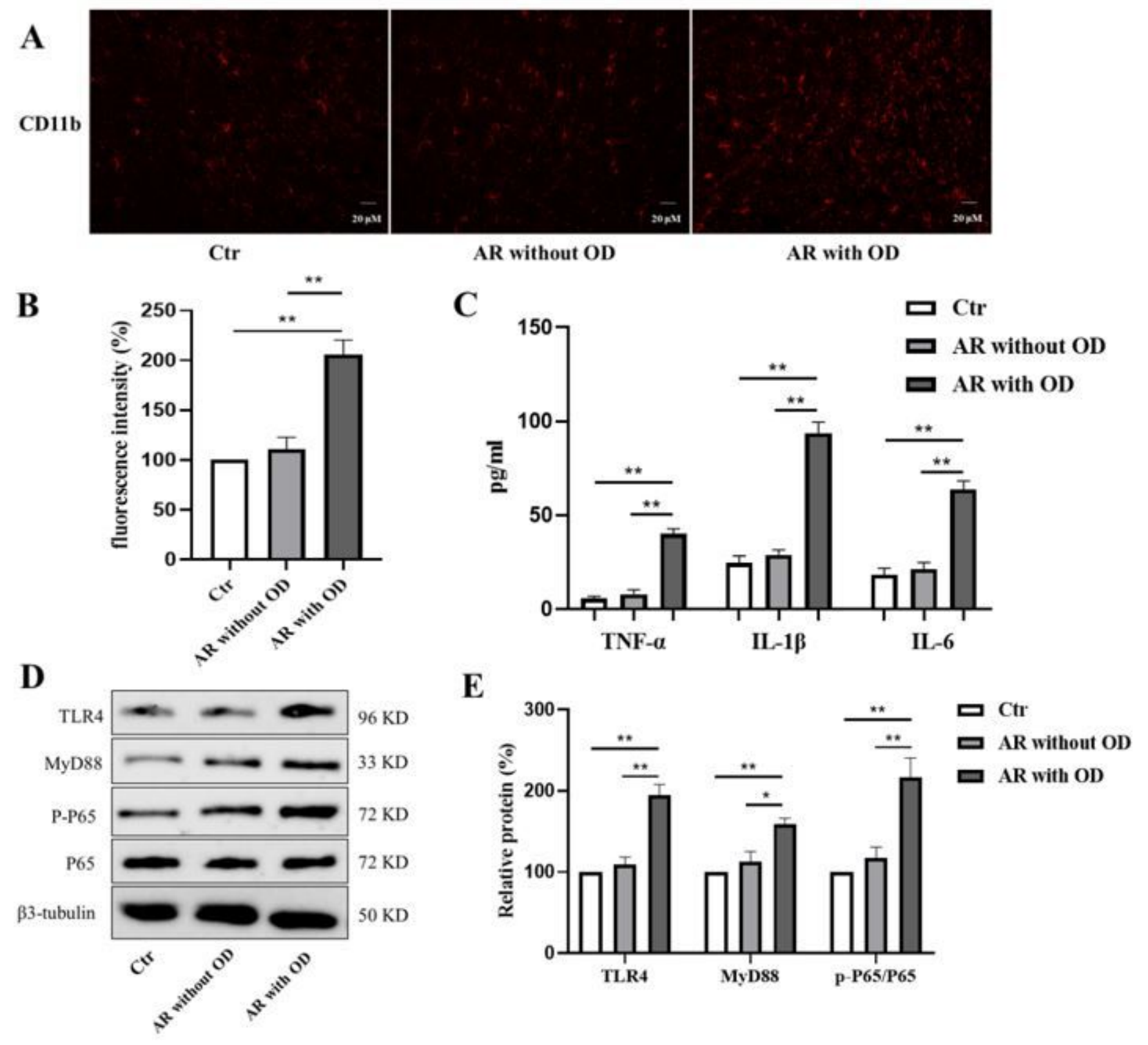

Figure 2

Hyperactivity of the microglia from the olfactory bulb in AR mice with OD. $a, b$ The expression of CD11b in the olfactory bulb was detected by immunofluorescence, and fluorescence intensity in each group of mice was analyzed. $c$ The expression of TNF-a, IL-1 $\beta$ and IL- 6 in the olfactory bulb was detected by ELISA. $d, e$ The expression of TLR4, MyD88, NF-KB P65 and NF-kB p-P65 in the olfactory bulb was detected by Western blot.* $\mathrm{P} \otimes 0.05$, ** $\mathrm{P} \otimes 0.01, \mathrm{n}=12$ 
A
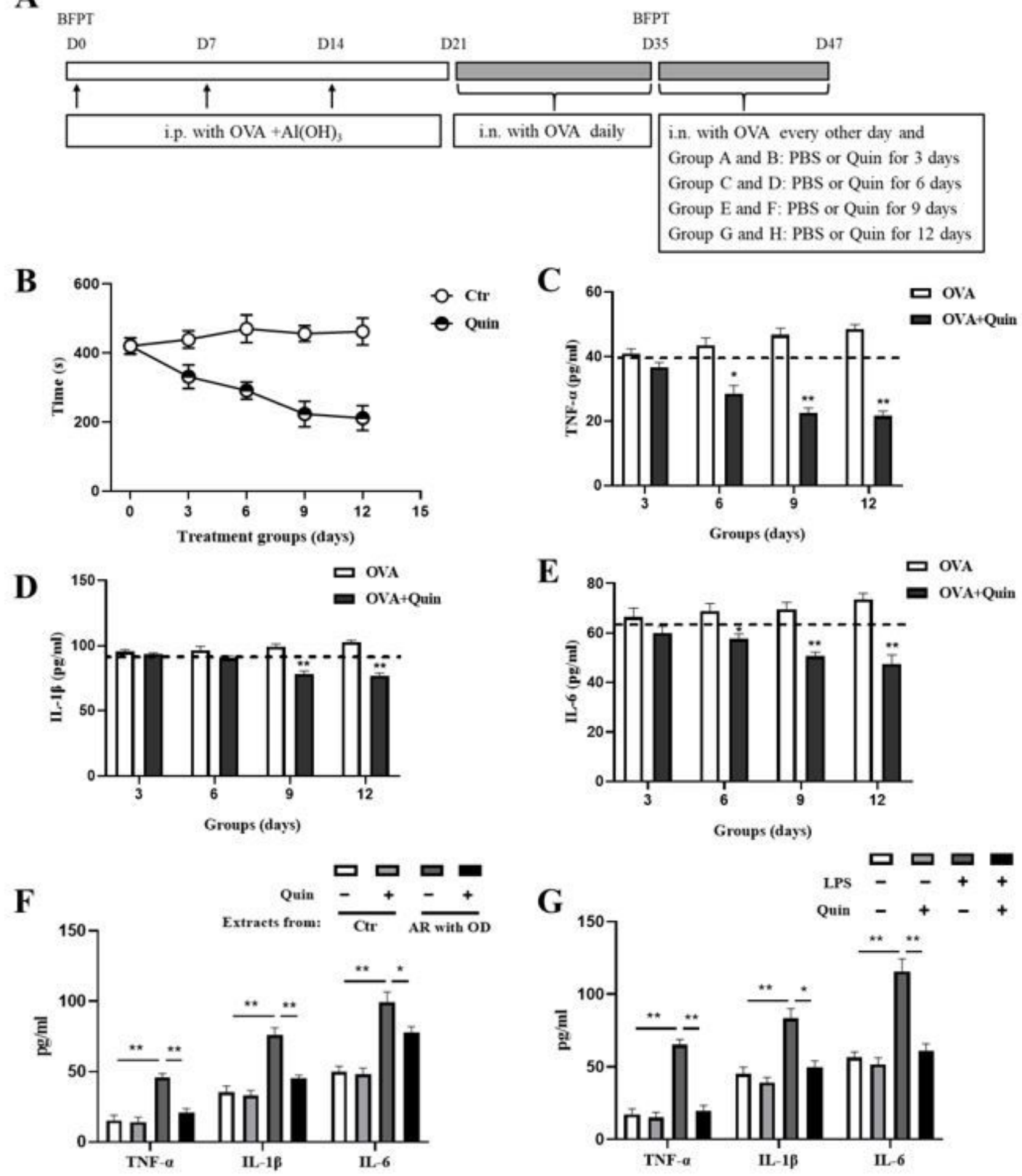

Figure 3

Quinpirole (Quin) improves microglia-dependent neuroinflammation in vivo and in vitro. a Protocol for the mice model of AR with OD and drug treatment grouping. i.p., Intraperitoneal; i.n., intranasal. b The effect of Quin for mice to find buried pellets. c, d, e The expression of TNF-a, IL-1 $\beta$ and IL- 6 in the olfactory bulb after treatment with Quin on days 3, 6, 9 and 12. $f$ The expression of TNF- $\alpha$, IL-1 $\beta$ and IL-6 in medium supernatant of microglias cultured in vitro after treatment with Quin for 24 hours. $g$ The effect of Quin on 
TNF- $a$, IL-1 $\beta$ and IL- 6 in medium supernatant of microglias cultured in vitro after 24 hours of LPS treatment. "--" represented the average on day $0 .{ }^{*} \mathrm{P} \bigotimes 0.05$, * $\mathrm{P} \rrbracket 0.01, \mathrm{n}=8$

A

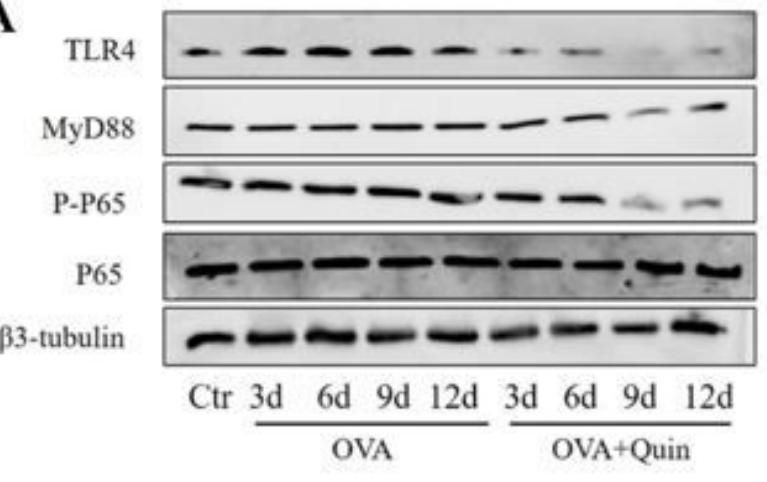

C

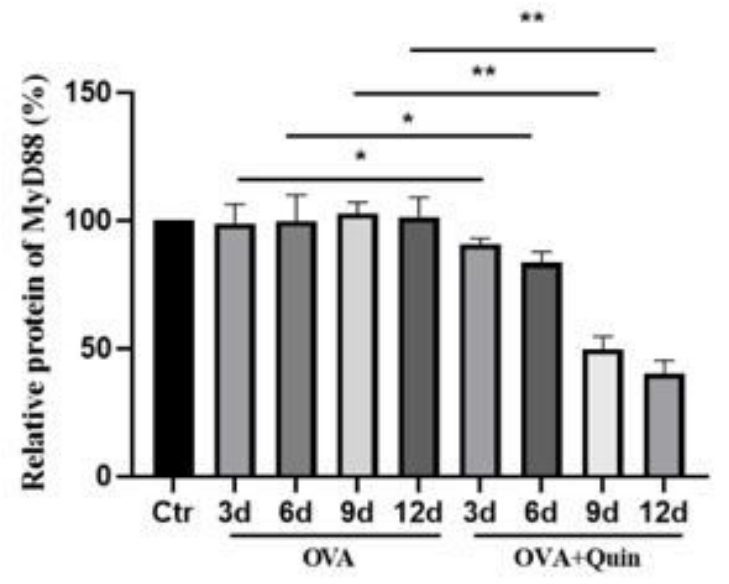

$96 \mathrm{KD}$

$33 \mathrm{KD}$

$72 \mathrm{KD}$

$72 \mathrm{KD}$

$50 \mathrm{KD}$

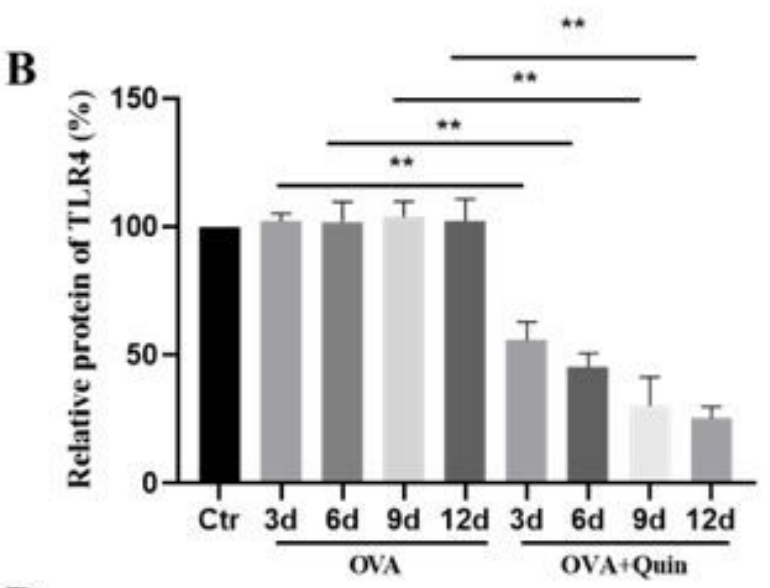

D

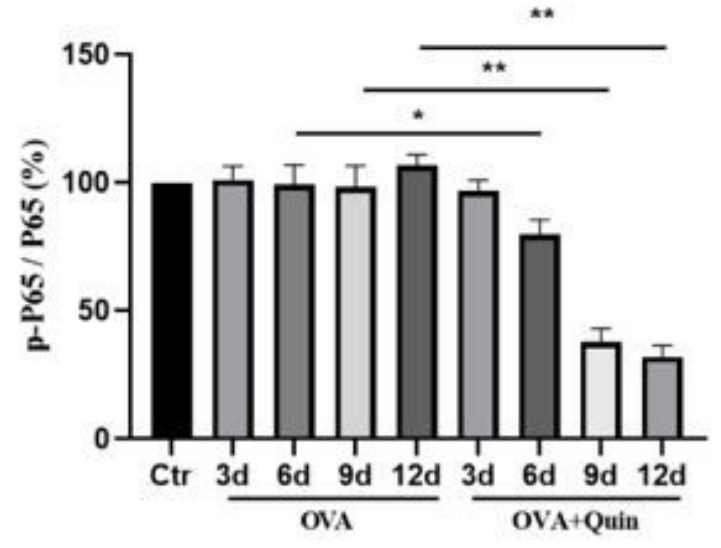

Figure 4

Quinpirole (Quin) inhibits TLR4/NF-KB pathway expression in vivo. a, b, c, d The effects of Quin on TLR4, MyD88, NF-kB P65 and NF-kB p-P65 on days 3, 6, 9 and 12. * Pख0.05, ** P®0.01, n=8 
A

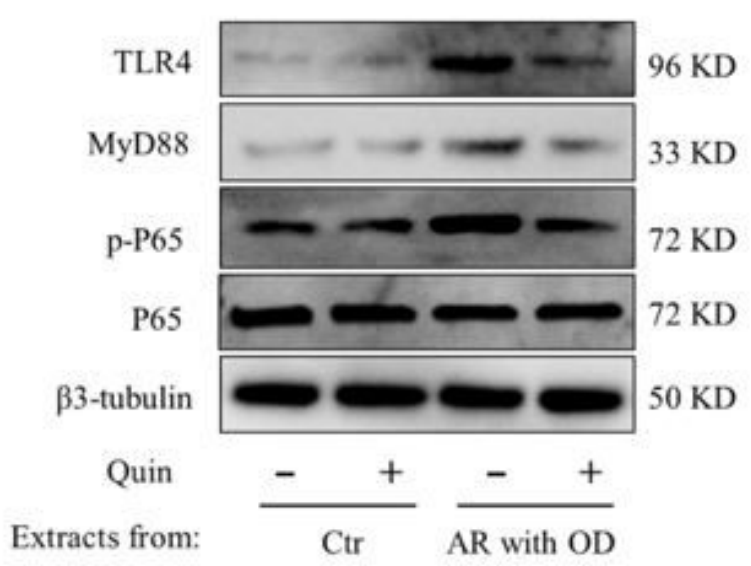

C

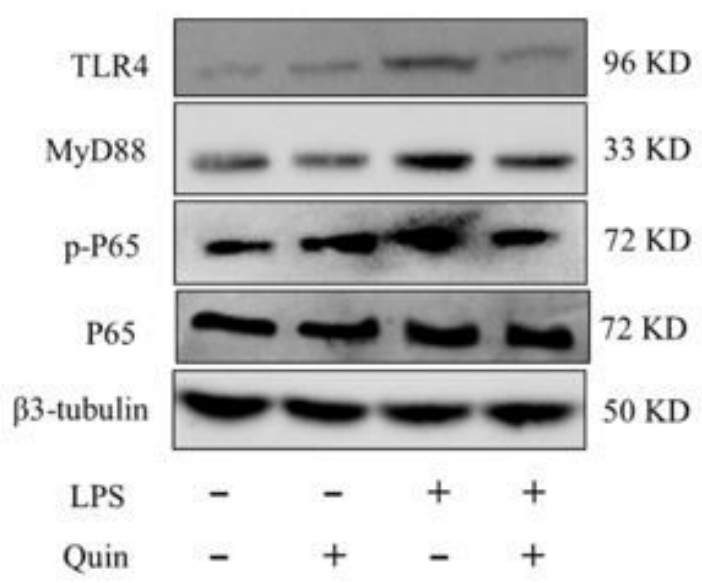

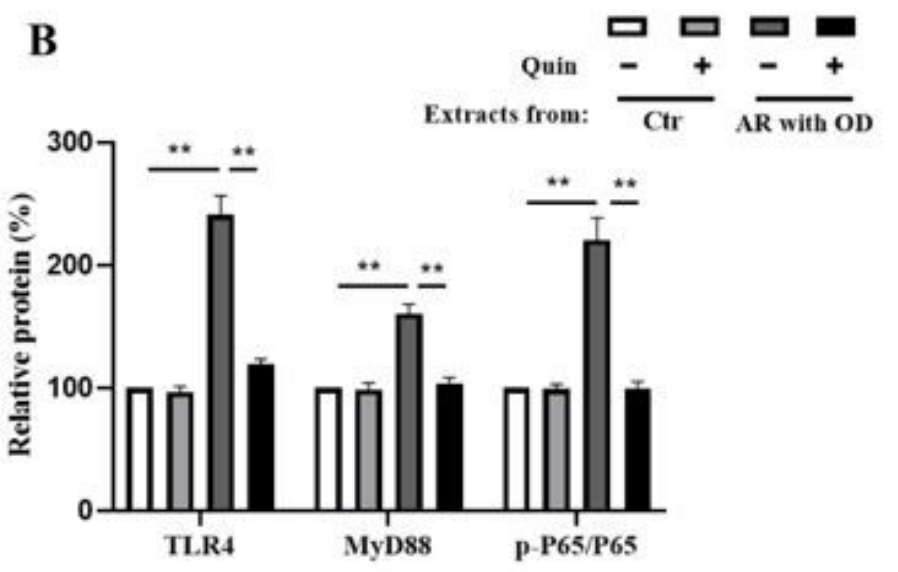
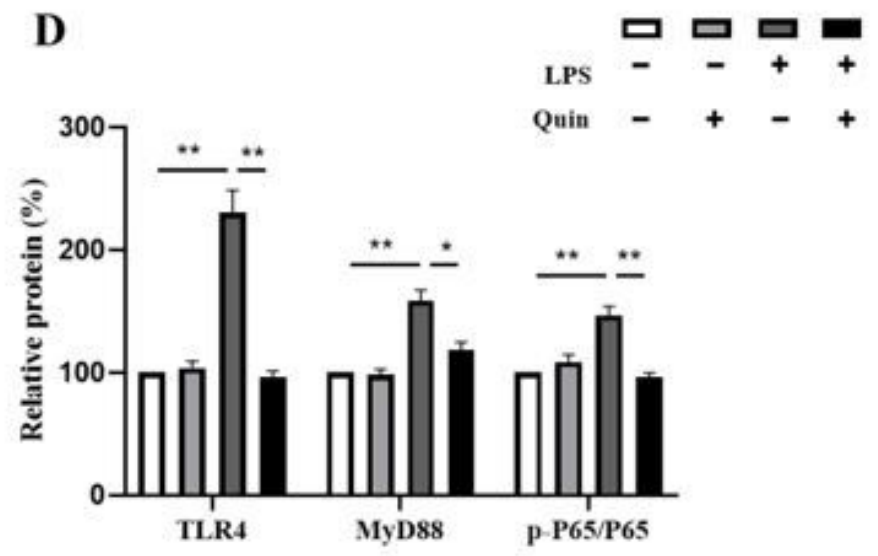

\section{Figure 5}

Quinpirole (Quin) inhibits TLR4/NF-KB pathway expression in vitro. $a, b$ In the coculture system of olfactory bulb neurons (OBNs) and microglias extracted from AR mice with OD, the expression of TLR4, MyD88, NF-kB P65 and NF-kB p-P65 of microglias after treatment with Quin for 24 hours. c, $d$ The effect of Quin on microglias in vivo after 24 hours of LPS treatment. * $P \bowtie 0.05$, ** $P \bowtie 0.01, n=8$ 


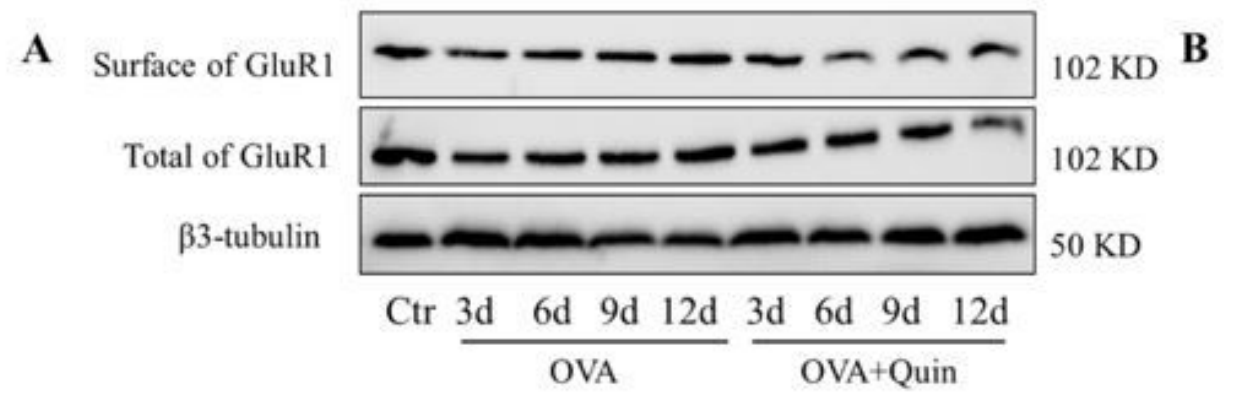

\section{C}

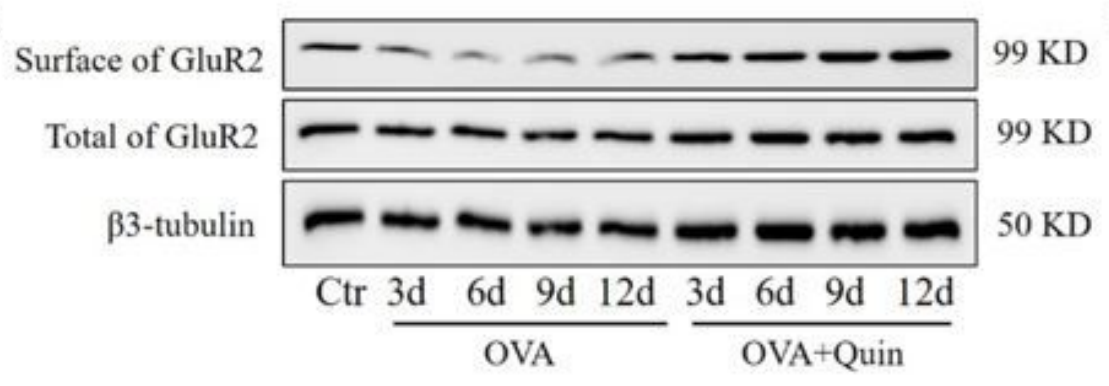

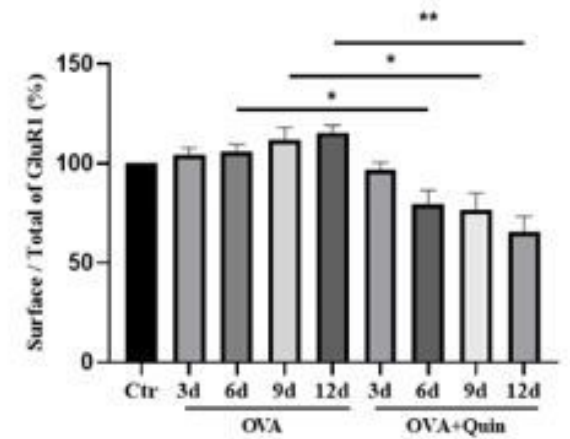

D

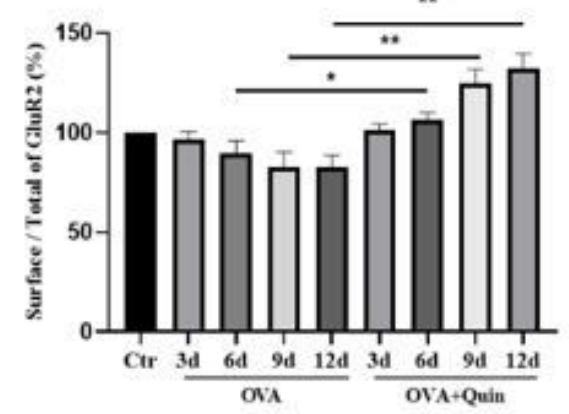

\section{Figure 6}

Quinpirole (Quin) improves AMPAR-mediated neuronal injury in vivo. a, b The effects of Quin on surface and total expression of GluR1 in the olfactory bulb on days 3, 6, 9 and 12. c, d The effects of Quin on surface and total expression of GluR2 in the olfactory bulb on days $3,6,9$ and $12 .{ }^{*} P \llbracket 0.05, * \star P \otimes 0.01, n=8$ 
A

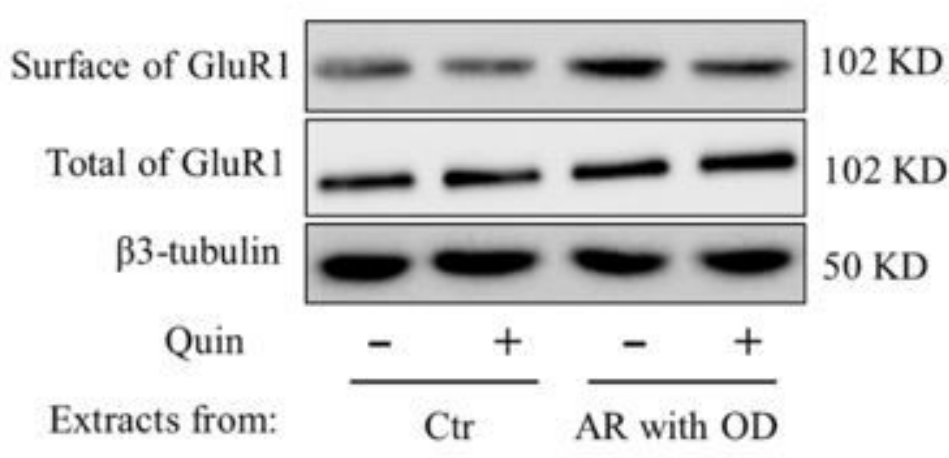

C Surface of GluR2

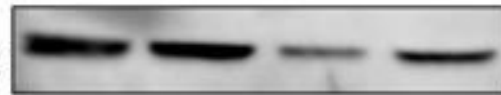

$99 \mathrm{KD}$

Total of GluR2

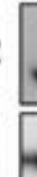

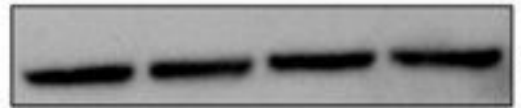

$99 \mathrm{KD}$

$\beta 3$-tubulin

Quin

Extracts from:

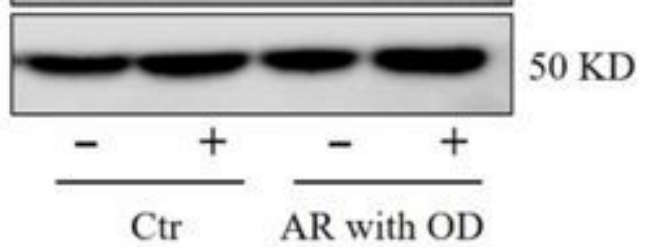

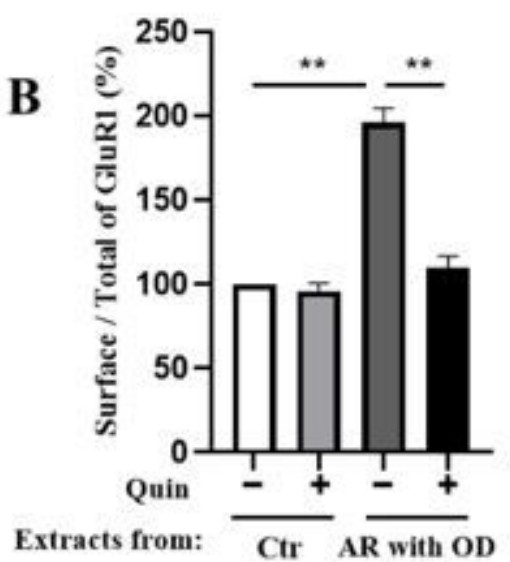
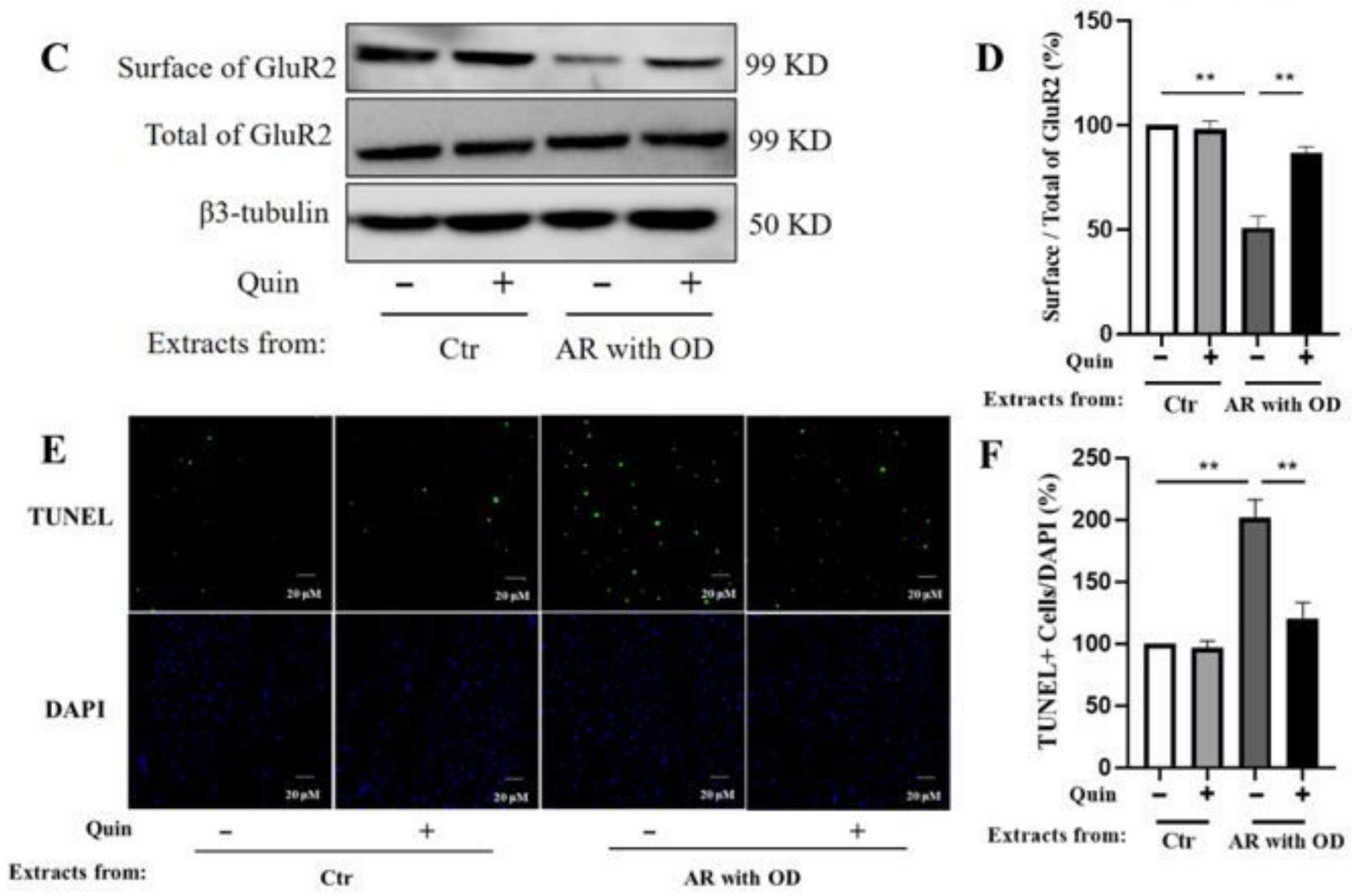

Extracts from: $\overline{\mathrm{Ctr}} \mathrm{AR}$ with $\mathrm{OD}$

F

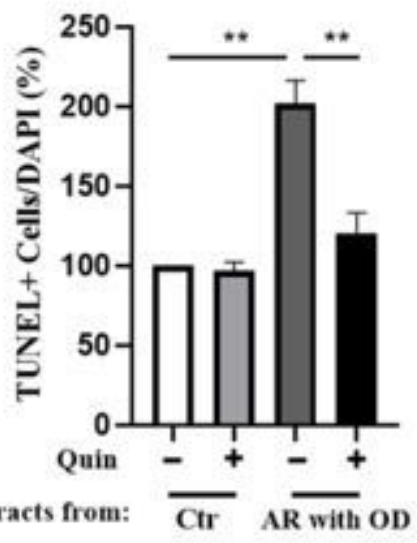

\section{Figure 7}

Quinpirole (Quin) improves neuronal injury in vitro. a, b, c, d The coculture system of OBNs and microglias extracted from AR mice with OD by treatment with Quin, the expression of surface and total of GluR1 and GluR2 of OBNs after 24 hours. e, $f$ The coculture system of microglias and OBNs by treatment with Quin, and apoptotic cells of OBNs were detected by TUNEL staining after 24 hours. ${ }^{*} \mathrm{P} \otimes 0.05,{ }^{\star \star} \mathrm{P} \otimes 0.01, \mathrm{n}=8$ 